\title{
Silica final lens performance in laser fusion facilities: HiPER and LIFE
}

\author{
D. Garoz ${ }^{1}$, R. González-Arrabal ${ }^{1}$, R. Juárez ${ }^{1,2}$, J. Álvarez ${ }^{1}$, \\ J. Sanz ${ }^{1,2}$, J.M. Perlado ${ }^{1}$ and A. Rivera ${ }^{1}$ \\ ${ }^{1}$ Instituto de Fusión Nuclear, UPM, José Gutiérrez Abascal 2, E28006 Madrid, Spain \\ ${ }^{2}$ Departamento de ingeniería energética, UNED, Juan del Rosal 12, E28040 Madrid, Spain \\ E-mail: david.garoz@upm.es
}

\begin{abstract}
Nowadays, the projects LIFE (Laser Inertial Fusion Energy) in USA and HiPER (High Power Laser Energy Research) in Europe are the most advanced ones to demonstrate laser fusion energy viability. One of the main points of concern to properly achieve ignition is the performance of the final optics (lenses) under the severe irradiation conditions that take place in fusion facilities. In this paper, we calculate the radiation fluxes and doses as well as the radiation-induced temperature enhancement and colour centre formation in final lenses assuming realistic geometrical configurations for HiPER and LIFE. On these bases, the mechanical stresses generated by the established temperature gradients are evaluated showing that from a mechanical point of view lenses only fulfil specifications if ions resulting from the imploding target are mitigated. The absorption coefficient of the lenses is calculated during reactor startup and steady-state operation. The obtained results reveal the necessity of new solutions to tackle ignition problems during the startup process for HiPER. Finally, we evaluate the effect of temperature gradients on focal length changes and lens surface deformations. In summary, we discuss the capabilities and weak points of silica lenses and propose alternatives to overcome predictable problems.
\end{abstract}

(Some figures may appear in colour only in the online journal)

\section{Introduction}

Fusion energy is foreseen to become within the next two decades a real competitor of fossil fuels with the added advantage of small environmental impact, safety and minimal waste generation. Nowadays, with the National Ignition Facility (NIF) in the last optimization stages to demonstrate ignition with energy gain, there is an increasing interest in nuclear fusion by inertial confinement with laser (laser fusion) as a commercial power source. Currently, the projects LIFE (Laser Inertial Fusion Energy) in USA and HiPER (High Power Laser Energy Research) in Europe are the most advanced ones to demonstrate laser fusion energy viability with indirect and direct drive targets, respectively.

The HiPER project [1-3] is at the end of the preparatory phase (phase 2). The next step (phase 3) will take place over the next seven years to carry out appropriate R\&D activities that eventually will lead to the construction of a demonstration (demo) power plant (phase 4). Since HiPER has adopted a risk reduction strategy based on achieving milestones before moving from one phase to the next, phase 4 indeed can be divided into two sub-phases: phase $4 a$, construction of an experimental facility to demonstrate an advanced ignition scheme and repetitive laser operation; phase $4 b$, construction of a demo power plant. Furthermore, we can devise a prototype facility as an intermediate step between the experimental facility and the demo power plant. The prototype facility does not imply any further construction work but a relaxed operation mode. This can be accomplished using low yield targets that allow one to study aspects such as target injection, tracking, repetition mode, heat extraction or tritium production while keeping material demands low. Moreover, the prototype facility operation mode will be especially useful to test materials under irradiation (as devised in LIFE. 1 [4], described next). Based on the NIF construction experience, the LIFE project [4-7] aims at the construction of a demo power plant, first with available technologies and existing materials (LIFE.1), and subsequently with improved capabilities (LIFE.2) based on the development of new technologies and materials in LIFE.1. A brief overview of the different development stages for the HiPER project and LIFE is summarized in table 1.

The development of materials able to withstand the harsh reactor environment is one of the main challenges to make fusion energy a reality. In particular, the development of materials with improved properties for the final optics components is a main point of concern since the ignition process itself depends on them. Special precautions need to 
Table 1. HiPER development strategy and LIFE scenarios.

\begin{tabular}{llllll}
\hline & $\begin{array}{l}\text { Experimental } \\
\text { facility }\end{array}$ & $\begin{array}{l}\text { Prototype } \\
\text { plant }\end{array}$ & Demo plant & LIFE.1 & LIFE.2 \\
\hline Operation & $\begin{array}{l}\text { Bunches of } \\
\text { 100 shots, max. }\end{array}$ & Continuous (24/7) & Continuous (24/7) & Continuous (24/7) & Continuous (24/7) \\
& 5 DT explosion & & & & \\
Yield (MJ) & $<20$ & $<50$ & $>100$ & 27 & 132 \\
Rep. rate (Hz) & $1-10$ & $1-10$ & $10-20$ & 16 & 16 \\
Power (GWt) & - & $<0.5$ & $1-3$ & 0.4 & 2.2 \\
T cycle & No & Yes & Yes & Yes & Yes \\
Blanket & No & Yes & Yes & Yes & Yes \\
\hline
\end{tabular}

be taken about the final lenses because they must face the target explosions only a few metres away during operation. Appropriate lenses must present (i) low laser absorption, (ii) good thermo-mechanical properties and (iii) high radiation resistance. Nowadays silica is proposed as the best candidate for final lenses, because of its good optical transparency from around $300 \mathrm{~nm}$ to the visible band (covering the second and third harmonic wavelengths of a typical solid-state laser), good thermo-mechanical properties, high radiation resistance and low cost $[8,9]$.

Previous works show that radiation generates point defects in silica. It is well known that fast neutron irradiation of silica gives rise to two main effects: network compaction (densification) [10] and point defect generation $[11,12]$. On the other hand, purely ionizing radiation plays a role in the formation of colour centres [13-15] which originates undesired laser absorption and scattering [16]. Moreover, simultaneous neutron and $\gamma$-ray irradiation (as is the case in a laser fusion reactor) leads to synergistic effects resulting in an enhanced degradation of the optical transmission properties $[9,17,18]$. In general, defects in silica are very complex. They can be charged or uncharged and interact among themselves giving rise to different configurations depending on temperature, stoichiometry and irradiation conditions $[19,20]$. Moreover, extrinsic defects, which can be inherent to the fabrication process, in particular hydrogen-related defects, play a crucial role in the radiation-induced defect configuration [21].

The purpose of this work is to estimate the performance of silica final lenses under realistic irradiation conditions for HiPER and LIFE. 2 facilities (table 1). For this purpose, firstly the radiation fluxes in the lenses are estimated. Secondly, the radiation-induced temperature enhancement, stress generation and colour centre formation (at a constant temperature) are determined. From these results the thermo-mechanical and optical (absorption) properties of the lenses are evaluated. Finally, the temperature enhancement and colour centre evolution during reactor startup are calculated. In summary, we illustrate the capabilities and weak points of silica lenses as final lenses and propose alternatives to overcome predictable problems.

\section{Chamber design}

HiPER chamber design is currently underway. However, some advanced concepts have already been studied [22,23]. A spherical reactor chamber has been proposed for the experimental facility with a $5 \mathrm{~m}$ inner radius and 48 openings for the laser beam lines for symmetrical target illumination.

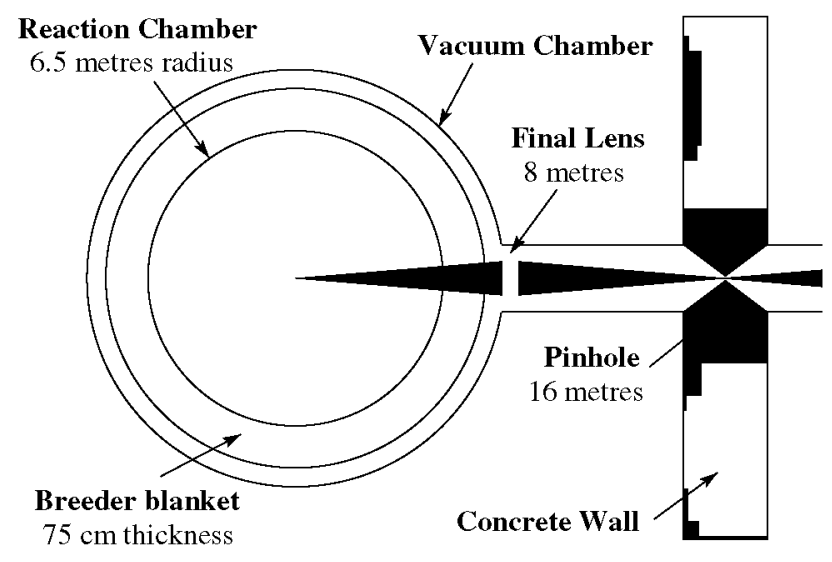

Figure 1. Schematic representation of the HiPER prototype and demo plants. Distances from the chamber centre are indicated.

The $10 \mathrm{~cm}$ thick chamber walls are surrounded by borated concrete to stop neutrons. On the other hand, the demo and prototype facilities have been devised as a $6.5 \mathrm{~m}$ inner radius steel chamber surrounded by a $75 \mathrm{~cm}$ thick breeder blanket (figure 1). In all cases lenses are located $8 \mathrm{~m}$ away from the chamber centre, to ensure a good focal spot on the target. As indicated in figure 1 , a thick concrete wall is located $16 \mathrm{~m}$ away from the chamber centre to protect the final optics components (except the final lenses). The laser beam passes through the wall by a thin opening (pinhole). The dimensions of the silica lenses are $75 \times 75 \mathrm{~cm}^{2}$ with a thickness of $5 \mathrm{~cm}$. Due to the circular shape of the chamber openings, only a $60 \mathrm{~cm}$ diameter circular area is directly exposed to the target. LIFE [6] will use $0.5 \mathrm{~cm}$ thick Fresnel final lenses located at $17 \mathrm{~m}$ from the chamber centre with dimensions large enough to accommodate the laser beams $\left(48 \times 48 \mathrm{~cm}^{2}\right)$.

\section{Radiation fluxes}

The radiation nature and fluxes in laser fusion depend on the type of target. In this work we follow the studies of direct and indirect targets carried out in the frame of the ARIES project ${ }^{3}$. Thus, we use the ARIES direct drive target with a yield of $154 \mathrm{MJ}$ to study the irradiation conditions of the final lenses in the HiPER demo power plant. For the prototype facility, the radiation spectra are rescaled to a target yield of $50 \mathrm{MJ}$ (table 1). In the case of a direct drive target, the most significant contributions are due to fusion neutrons ( $\sim 71 \%$ of target yield)

\footnotetext{
${ }^{3}$ http://aries.ucsd.edu/ARIES/WDOCS/ARIES-IFE/SPECTRA/
} 


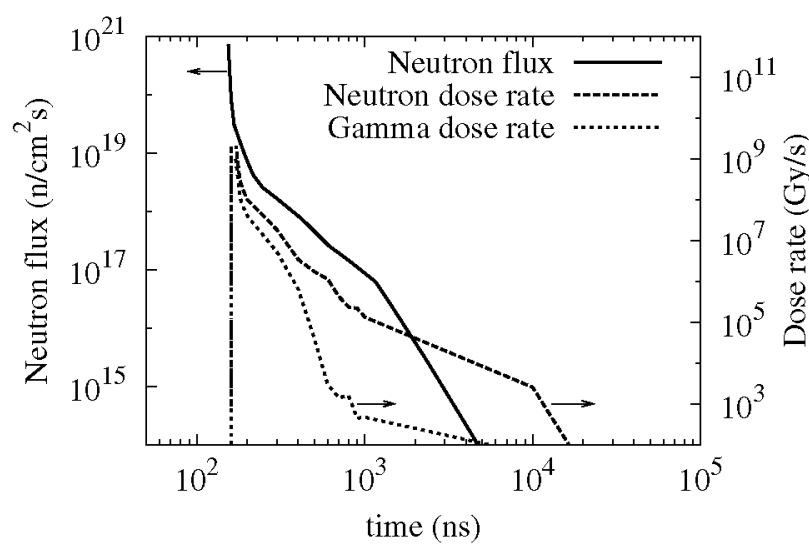

Figure 2. Primary neutron flux, total neutron and gamma dose rates as a function of time after each explosion in a final lens of the HiPER demo plant with a $154 \mathrm{MJ}$ yield target.

and ions (burn products and debris) that carry nearly $27 \%$ of the total energy released by the explosion $[24,25]$. In the case of indirect-drive targets (as in LIFE) in addition to fusion neutrons ( $\sim 69 \%$ of the target yield) and to high energy ions which carry $\sim 6 \%$ of the total energy released by the explosion, a large fraction of $x$-rays are generated due to the hohlraum accounting up to $25 \%$ of the target yield $[24,25]$. Thus, the major difference is the important $\mathrm{x}$-ray contribution generated in subns timescales with indirect targets leading to a huge power deposition on the surrounding materials, which could not withstand the thermo-mechanical shock without appropriate mitigation strategies (for example, filling the chamber with residual gas) $[7,24,26]$.

On this basis, the neutron and $\gamma$-ray doses absorbed by the silica lenses in HiPER were accurately calculated as a function of time with MCNPX [27] for the HiPER prototype and demo reactor geometry described in section 2 . The reactor geometry was designed with CATIA and converted with MCAM [28] into a valid geometrical input for MCNPX. The mean free paths were obtained from the ENDF-VII data base [29]. The results for the HiPER demo reactor are shown in figure 2. A high neutron flux (corresponding to primary neutrons) is observed immediately after the explosion which rapidly decreases up to three orders of magnitude within the first $60 \mathrm{~ns}$. The total neutron dose rate calculated with MCNPX follows the same trend. Due to $(n, \gamma)$ reactions a significant $\gamma$-pulse accompanies the emission of neutrons. These results indicate that the final lenses receive concomitant neutron and gamma pulses after every explosion. It is worthwhile to mention that for the prototype reactor the curves follow the same time dependence but the absolute values are a factor of $1 / 3$ lower than those depicted in figure 2.

The neutron and $\gamma$-ray doses absorbed by the final lenses in LIFE. 2 were estimated from the $458 \mathrm{MJ} \mathrm{HI}$ indirect-drive target [24] rescaled to $132 \mathrm{MJ}$. Because of the unknown complete reactor chamber geometry, the neutron flux $\left(\Phi_{n}\right)$ was calculated using only direct neutrons of energy $E_{n}$. Then, the neutron dose rate was obtained as follows

$$
\begin{gathered}
\dot{D}_{\mathrm{n}}=\frac{\Phi_{\mathrm{n}} E_{\mathrm{PKA}}}{d \rho_{\mathrm{SiO}_{2}}}\left[1-\exp \left(\frac{-d}{\lambda_{\mathrm{n}}}\right)\right] \\
\text { with } E_{\mathrm{PKA}}=\frac{2}{M+2 / 3} E_{\mathrm{n}},
\end{gathered}
$$

where $\lambda_{\mathrm{n}}$ is the mean free path, $d$ the lens thickness, $\rho_{\mathrm{SiO}_{2}}$ is the density and $M$ is the average atomic mass (20 for $\mathrm{SiO}_{2}$ ). According to the previous calculations carried out with MCNPX for the HiPER demo reactor (figure 2) and for the HiPER experimental facility [30] the gamma dose is assumed to be 0.4 times the neutron dose.

The estimated radiation mean energy, pulse width and mean range (penetration depth) values at HiPER final lenses are depicted in table 2. Mean energy and pulse width were estimated from ARIES direct drive with a yield of $154 \mathrm{MJ}$ $[24,31]$, except $x$-ray pulse width taken from [32]. Ion mean range was calculated by means of SRIM code ${ }^{4}\left[33\right.$ ] and $\mathrm{x}^{-}$ ray mean range using appropriated absorption coefficients ${ }^{5}$ In addition, the total energy density (ED) deposited by each radiation form is also shown for HiPER and LIFE.2 lenses, which are located at $8 \mathrm{~m}$ and $17 \mathrm{~m}$, respectively. As shown in table 2, the deposited energy by neutrons and gammas in LIFE. 2 and in HiPER prototype lenses is quite similar.

\section{Thermo-mechanical response}

The radiation-induced thermo-mechanical response of the lenses was calculated by means of the finite element solver Code Aster ${ }^{6}$ [34]. In order to speed up calculations, the lenses were assumed to have cylindrical geometry with a diameter of $75 \mathrm{~cm}$ and a thickness of $5 \mathrm{~cm}$ for HiPER and a diameter of $70 \mathrm{~cm}$ and thickness of $0.5 \mathrm{~cm}$ for LIFE.2. As shown in figure 3 , these geometries were modelled by an axis-symmetric 2D mesh using Salome Platform ${ }^{7}$. Moreover, to achieve a detailed estimation of the temperature gradients and local stresses, the mesh was refined with small elements of $100 \mathrm{~nm}$ along the axial direction $(z)$ at the inner surface and in the radial direction $(r)$ at the irradiated/unirradiated boundary $(r=30 \mathrm{~cm}$ for HiPER and $r=24 \mathrm{~cm}$ for LIFE.2). The lens surfaces were supposed to emit radiation and the lens surrounding temperature was considered to be constant. The radiation emitted through the lens surfaces was calculated according to the StephanBoltzmann law. The mechanical boundary conditions were determined by the axis-symmetric geometry.

\subsection{HiPER}

After every explosion the final lenses have to withstand high thermal loads in the form of ions, $\mathrm{x}$-rays, neutrons and gammas. The radiation-induced thermal loads mainly depend on the radiation flux and nature. Since the irradiation in laser fusion is pulsed (consequence of target explosions), the energy deposition takes place within a few microseconds after the explosion, starting with $\mathrm{x}$-ray and finishing with the last debris ions that reach the lens (table 2). Ions and $\mathrm{x}$-rays deposit almost all of their energy in the first few micrometres $(<10 \mu \mathrm{m})$ beneath the inner lens surface, whereas neutrons and gammas deliver their energy (almost) homogeneously along the lens volume.

As shown in table 2, the ED deposited by ions is $1230 \mathrm{~J} \mathrm{~cm}^{-3}$ and $3788 \mathrm{~J} \mathrm{~cm}^{-3}$ for HiPER prototype and

\footnotetext{
4 www.srim.org/

5 http://physics.nist.gov/PhysRefData/XrayMassCoef/

www.code-aster.org/

7 www.salome-platform.org/
} 
Table 2. Mean energy, pulse width, mean range and ED deposited in lenses by each radiation form in different scenarios for HiPER and LIFE. 2.

\begin{tabular}{lllllllll}
\hline & \multicolumn{7}{c}{ HiPER $(8 \mathrm{~m})$} & LIFE.2 $(17 \mathrm{~m})$ \\
\cline { 2 - 6 } & $\begin{array}{l}\text { Mean } \\
\text { energy } \\
(\mathrm{MeV})\end{array}$ & $\begin{array}{l}\text { Pulse } \\
\text { width } \\
(\mathrm{ns})\end{array}$ & $\begin{array}{l}\text { Mean } \\
\text { range } \\
(\mu \mathrm{m})\end{array}$ & $\begin{array}{l}\text { ED } \\
\text { in experim. } \\
\left(\mathrm{J} \mathrm{cm}^{-3}\right)\end{array}$ & $\begin{array}{l}\text { ED } \\
\text { prototype } \\
\left(\mathrm{J} \mathrm{cm}^{-3}\right)\end{array}$ & $\begin{array}{l}\text { ED } \\
\text { demo } \\
\left(\mathrm{J} \mathrm{cm}^{-3}\right)\end{array}$ & $\begin{array}{l}\text { ED } \\
\text { LIFE.2 } \\
\left(\mathrm{J} \mathrm{cm}^{-3}\right)\end{array}$ \\
\hline Burn products $\left({ }^{4} \mathrm{He}\right)$ & 2.1 & 400 & 6.4 & 492 & 1230 & 3788 & $-^{a}$ \\
Debris ions $(\mathrm{D}, \mathrm{T})$ & 0.15 & 2200 & 1.4 & 2549 & 6372.7 & 19628 & $-^{a}$ \\
X-rays & 0.007 & 0.17 & 10 & 34 & 85 & 261 & $-^{a}$ \\
Neutrons & 12.4 & 60 & - & 0.018 & 0.046 & 0.142 & 0.03 \\
Gammas & - & $\approx 60$ & - & 0.007 & 0.017 & 0.051 & 0.012 \\
\hline
\end{tabular}

${ }^{a}$ Gas protection avoids thermal shock due to ions and $x$-rays in LIFE lenses.

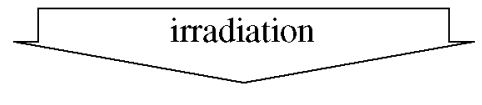

inner surface

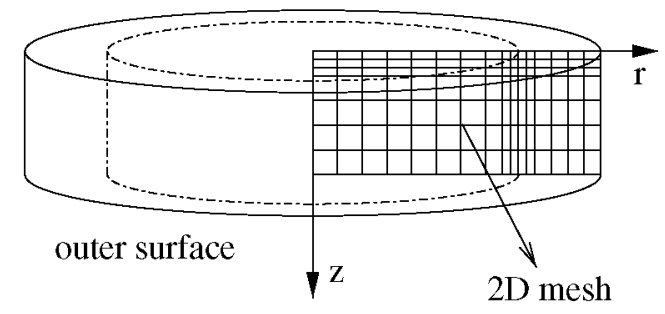

Figure 3. Representation of a cylindrical lens irradiated parallel to the lens axis $(z)$. The $2 \mathrm{D}$ mesh employed for the calculations is schematically shown. It is formed by elements of different dimensions.

demo reactors, respectively. Such a density would lead to temperature enhancements higher than the silica melting temperature in just one shot. Therefore, ions must be somehow mitigated [35]. Details on ion mitigation are beyond the scope of this paper. We will simply assume from now on that ion mitigation occurs.

The experimental facility will operate in bunch mode at room temperature; therefore, the lens temperature prior to the pulse arrival can be considered uniform. On the other hand, the prototype and demo reactors will operate in continuous mode. Assuming a steady-state situation for the prototype reactor the lens surface temperature will be $866 \mathrm{~K}$ and higher at the centre at the beginning of the pulse (see discussion below and figure 5(a)). Disregarding ions, the major contribution to the temperature enhancement at depths $\leqslant 10 \mu \mathrm{m}$ is due to $\mathrm{x}$-rays. The radiation-induced temperature enhancement as a function of time after one explosion at several depths underneath the lens inner surface is depicted in figures $4(a)$ and $(b)$ for the HiPER experimental and prototype reactor, respectively. The surface temperature increases $7 \mathrm{~K}$ for the experimental and $15 \mathrm{~K}$ for the prototype reactor. The temperature drops fast as a function of time after the explosion and as a function of the distance from the lens surface. The temperature gradient at depths $\leqslant 10 \mu \mathrm{m}$ disappears after $100 \mu \mathrm{s}$ and the temperature at a depth of $10 \mu \mathrm{m}$ increases only $2 \mathrm{~K}$ due to the heat transferred by conduction from the inner surface. In the case of the prototype reactor, the neutron and $\gamma$-ray contribution leads to a temperature rise of about $0.1 \mathrm{~K}$ per shot along the whole lens thickness. This contribution is negligible for the experimental reactor. The temperature rise generates cyclic stress at the irradiated inner surface depths $\leqslant 10 \mu \mathrm{m}$, see figures $4(c)$ and $(d)$. The $\mathrm{x}-$ ray thermal shock increases the volume of the inner surface material generating compression stress. In the case of the prototype facility, figure $4(d)$, the initial traction radial stress due to the initial temperature decreases until compression values are reached at depths $\leqslant 0.5 \mu \mathrm{m}$.

When working in continuous mode, the average lens temperature increases if the energy deposited in one pulse is higher than that radiated by the lens surfaces. When both contributions balance each other, the steady state is achieved. The maximum temperature in the steady state depends on the surrounding temperature. In this particular case since the lens location is close to the breeder blanket, the surrounding temperature is assumed to be similar to that of the breeder blanket (i.e. $>600 \mathrm{~K}$, being this value the lower operation limit). Assuming that the lens temperature is equal to the surrounding temperature before the startup reactor $\left(T_{0}=\right.$ $600 \mathrm{~K})$, the steady-state maximum temperature into the lens reaches $938 \mathrm{~K}$ for the prototype reactor and $1304 \mathrm{~K}$ for the demo reactor, below and above the maximum silica service temperature $(1223 \mathrm{~K})$, respectively, see table 3 . The steadystate situation occurs after 32000 pulses for the prototype reactor and after 25000 pulses for the demo reactor. Note that in continuous mode the neutron and gamma contributions are very relevant since (ignoring ions) they carry most of the energy. The energy deposited by laser absorption is negligible (and therefore not considered here) because the high temperature reached in continuous mode keeps the optical absorption low (see section 5). Therefore, even when disregarding ions, we conclude that silica lenses cannot operate under HiPER demo reactor conditions in the present configuration. A possible solution could be to use external coolers for the lenses or to modify the optical configuration moving the final lenses further away from the chamber centre. Both possibilities imply a detailed study beyond the scope of this work.

The 2D temperature profile and stresses under steadystate conditions for the prototype facility are depicted in figure 5(a). The lenses reach a maximum internal temperature of $938 \mathrm{~K}$, with $866 \mathrm{~K}$ at the inner surface where $\mathrm{x}$-rays are deposited and $826 \mathrm{~K}$ at the outer surface. The coolest area is the lateral surface $(r=37.5 \mathrm{~cm})$ which corresponds to the unirradiated volume. The temperature gradients along the $z$ and $r$ directions lead to stress generation. The temperature distribution in $z$ is mainly responsible for radial and azimuthal gradient stresses within the irradiated volume along $z$. In particular, tractions of 0.46 and of $0.71 \mathrm{MPa}$ are observed at 

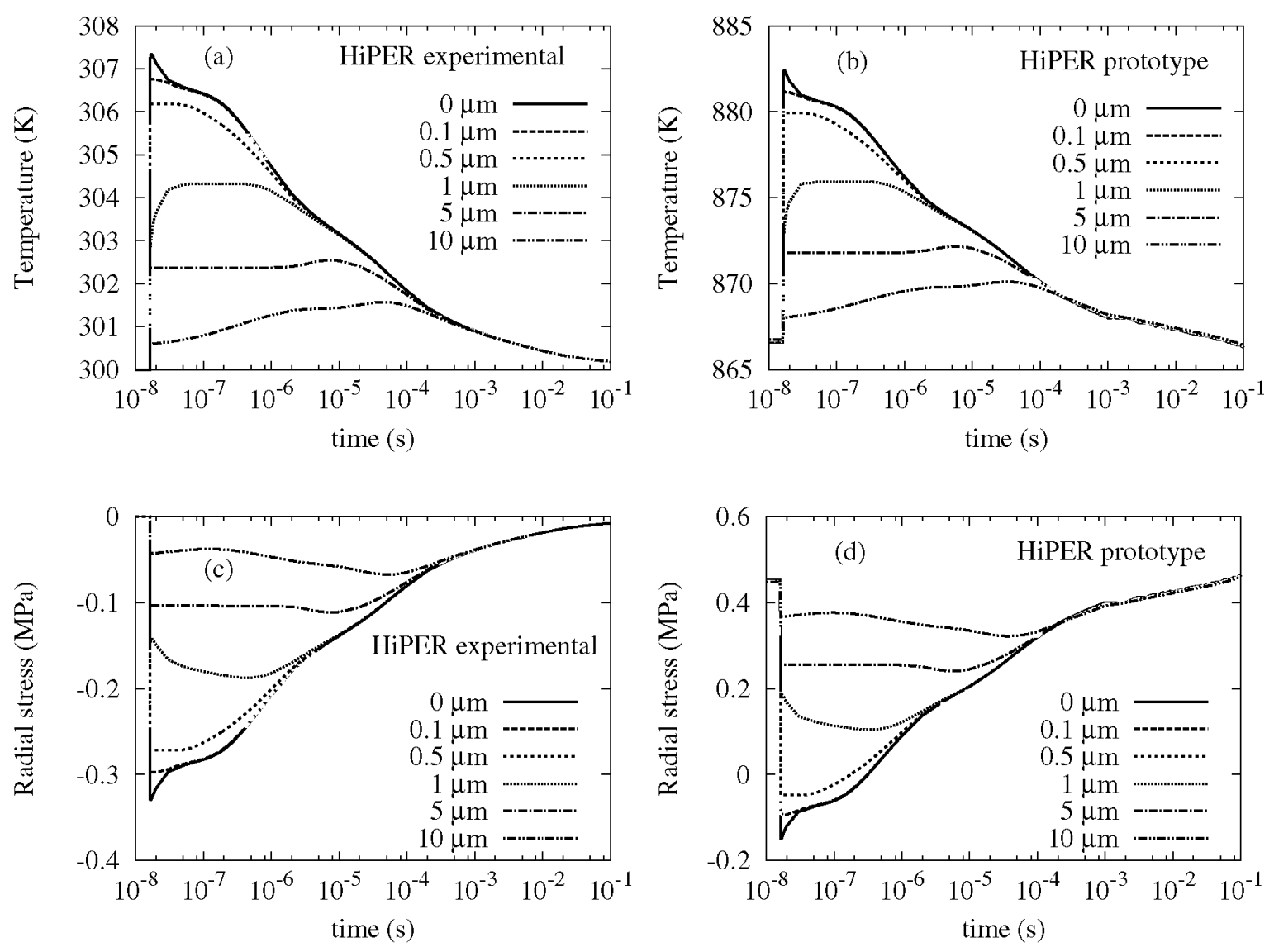

Figure 4. Final lens temperature as function of time after each explosion for different depths in the HiPER experimental facility (a) and in the prototype facility $(b)$. Radial stress evolution at different depths for experimental facility $(c)$ and for the prototype facility $(d)$.

the lens inner and outer surfaces, respectively. A compressive stress of $-2.75 \mathrm{MPa}$ is calculated at the centre of the lens where the temperature reaches its maximum value. Significant contribution neither to axial nor to shear stress is observed related to the temperature distribution along $z$. The fact that the temperature of the unirradiated volume is around $600 \mathrm{~K}$ impedes the lens expansion in $r$ directions. A compressive stress for $r<30 \mathrm{~cm}$, traction for $r>30 \mathrm{~cm}$, as well as axial and shear stresses at $r=30 \mathrm{~cm}$ are generated due to the temperature gradient along the $r$ direction. In all cases the calculated stresses are observed to be lower than the silica tensile strength ( $48 \mathrm{MPa}$ ) which indicates that, as a fair simplification, silica lenses can withstand the radiationinduced mechanical stresses.

In order to have a more detailed picture of silica mechanical behaviour it must be considered that silica can suffer brittle fracture by crack generation and growth. The lenses can have preexisting cracks due to the fabrication process or due to their manipulation. In addition, operation may lead to crack generation stemming from irradiation induced-point defects. Moreover, the impact of shrapnel from the target explosions (especially relevant with indirect targets) may generate cracks at the inner surface of lenses.

The intensity factor in traction (mode I [36]), $K_{\mathrm{I}}=$ $\sigma_{\max } \sqrt{\pi a}$, allows one to predict the stress state near the tip of an existing crack with a length of $2 a$ caused by the maximum traction stress $\sigma_{\max }$. Under the assumption of linear elastic fracture mechanics [36], cracks start to grow when the
Table 3. Calculated thermo-mechanical values and critical limits for silica. $T_{\max }$ is the maximum temperature, $\sigma_{\max }$ is the maximum traction stress, $(2 a)_{\mathrm{c}}$ the critical crack length and $\Delta K_{\mathrm{I}}$ the stress intensity factor range assuming $1 \mu \mathrm{m}$ long cracks.

\begin{tabular}{llllll}
\hline & & & & & $\begin{array}{l}\text { Critical } \\
\text { HiPER } \\
\text { experimental }\end{array}$ \\
& $\begin{array}{l}\text { HiPER } \\
\text { prototype }\end{array}$ & $\begin{array}{l}\text { HiPER } \\
\text { demo }\end{array}$ & $\begin{array}{l}\text { LIFE.2 } \\
\text { of silica }\end{array}$ \\
\hline$T_{\max }(\mathrm{K})$ & 307 & 938 & 1304 & 744 & 1223 \\
$\sigma_{\max }(\mathrm{MPa})$ & 0.12 & 7.1 & 9.2 & 3.25 & 48 \\
$(2 a)_{\mathrm{c}}(\mathrm{mm})$ & $>2 \times 10^{4}$ & 6.73 & 2.04 & 32.12 & - \\
$\left.\Delta K_{\mathrm{I}}(\mathrm{MPa} \mathrm{m})^{1 / 2}\right)$ & $1.5 \times 10^{-4}$ & $5.8 \times 10^{-4}$ & $10^{-3}$ & 0 & 0.3 \\
\hline
\end{tabular}

intensity factor is equal to or larger than the fracture toughness $\left(K_{\text {IC }}=0.73 \mathrm{MPa} \mathrm{m}^{1 / 2}\right.$ for silica [37]). Therefore, knowing the maximum traction stress for each scenario, one can estimate the critical crack length for brittle fracture to occur. As shown in table 3, the critical crack length for the HiPER experimental facility is higher than the lens dimensions, which indicates that silica lenses will not suffer brittle fracture. The estimated critical lengths for a HiPER prototype and demo reactors are $6.73 \mathrm{~mm}$ and $2.04 \mathrm{~mm}$, respectively. Thus, longer cracks would lead to brittle fracture of the lenses. In order to prevent the failure of HiPER lenses in continuous mode, preexisting cracks near the lateral surface $(r=37.5 \mathrm{~cm})$ must be avoided during manufacture and subsequent manipulation.

Moreover, one also has to consider the effect of fatigue. Cracks can grow due to cyclic fatigue induced by traction cyclic 


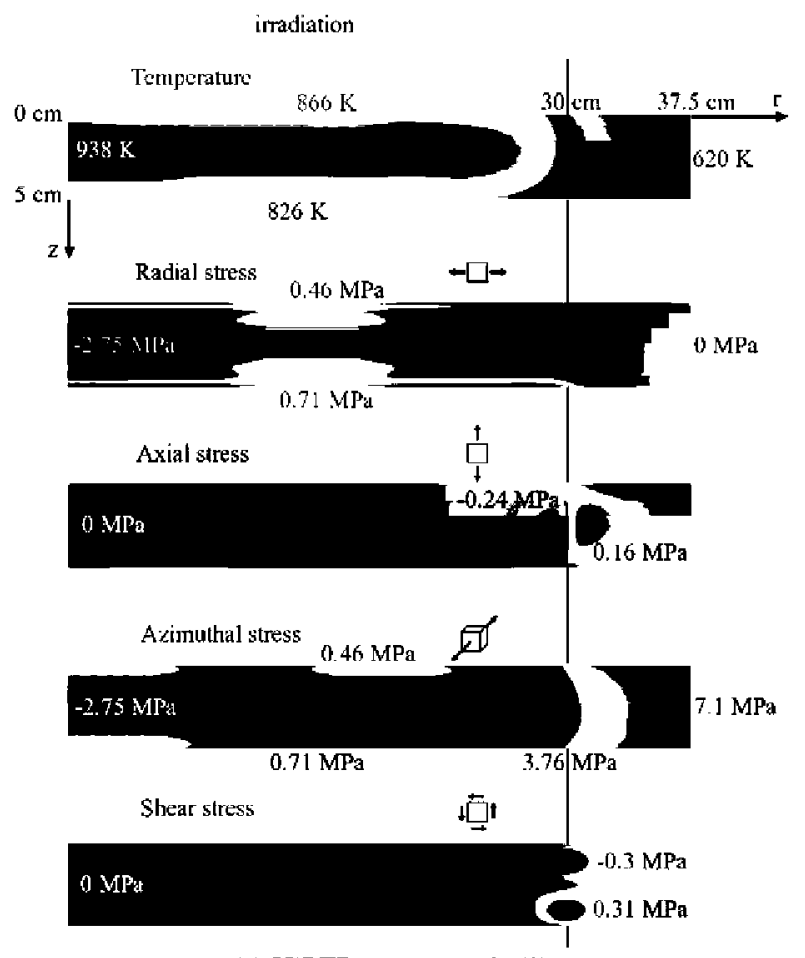

(a) HiPER prototype facility
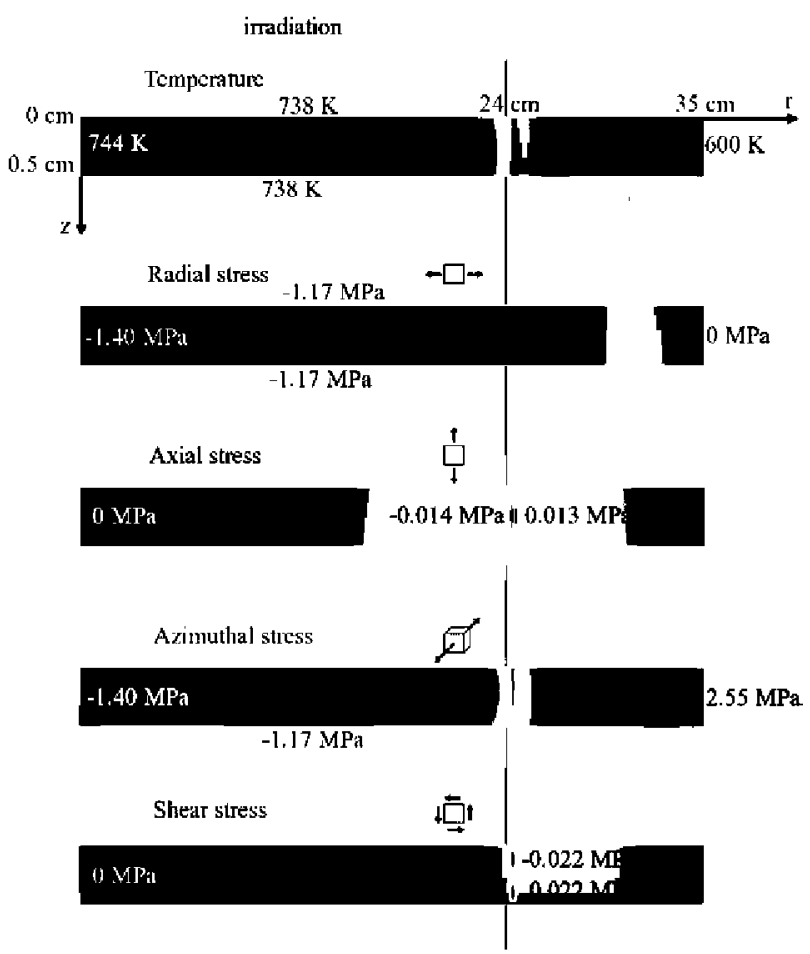

(b) LIFE.2 power plant

Figure 5. 2D colour maps of temperature and of radial, axial, azimuthal and shear stresses at the end of each pulse in steady-state operation conditions for the HiPER prototype facility $(a)$ and for the LIFE.2 facility $(b)$.

stresses. The x-ray thermal shock generates cyclic stresses near the inner surface. In the experimental facility the axial traction stress at $r=30 \mathrm{~cm}$ varies from $0.12 \mathrm{MPa}$ to zero along a distance of around $1 \mu \mathrm{m}$ (not shown in figures). The cyclic stresses in the prototype and demo extend up to $1 \mu \mathrm{m}$ depth at the irradiated inner surface, see figure $4(d)$ for the prototype. The traction stress range $\Delta \sigma$ is $0.12 \mathrm{MPa}$ for the experimental facility, $0.46 \mathrm{MPa}$ for the prototype reactor and $0.52 \mathrm{MPa}$ for the demo reactor. On these bases, one can estimate the stress intensity factor range for each facility with $\Delta K_{\mathrm{I}}=\Delta \sigma \sqrt{\pi a}$, assuming $1 \mu \mathrm{m}$ crack length, which is equal to the volume affected by the traction cyclic stresses. The stress intensity factor ranges have been estimated in table 3 . In all scenarios the stress intensity factor range is well below the fatigue threshold of silica, $\Delta K_{\text {th }}=0.3 \mathrm{MPa} \mathrm{m}^{1 / 2}$ [38], therefore the probability of crack growth due to cyclic fatigue is negligible.

In conclusion, silica lenses in the experimental and prototype facility appear to withstand the thermo-mechanical conditions imposed by the irradiation conditions (assuming ion mitigation). On the other hand, the lenses will not operate under the demo reactor's extreme irradiation conditions (even assuming ion mitigation).

\subsection{LIFE. 2}

Due to the intense $x$-ray pulses resulting from indirect target explosions, mitigation strategies are a must to protect the chamber components. Usually, gas protection scenarios are proposed as is the case for LIFE. Thus, the prompt irradiation that reaches the lenses is mainly in the form of neutron and gamma pulses. In order to properly calculate the energy deposited in the lenses one must also take into account the laser contribution because in this case the maximum temperatures are too low to keep the optical absorption low (see section 5). The heat flux due to laser irradiation is determined as follows [18]:

$$
q_{\text {laser }}=F_{\text {laser }} v(1-\exp (-A d)),
$$

where $F_{\text {laser }}$ is the laser fluence, $v$ is the frequency, $A$ is the absorption coefficient and $d$ is the lens thickness. By considering an optical absorption coefficient of $3.9 \%$ (see section 5) the heat flux is estimated to be $0.17 \mathrm{~J} \mathrm{~cm}^{-3}$. On this basis, the total deposited heat (ED) is calculated to be $0.212 \mathrm{~J} \mathrm{~cm}^{-3}$. Such an energy deposition leads to a temperature rise of $0.01 \mathrm{~K}$ per pulse, which is almost homogeneous along the whole lens thickness.

As previously illustrated the steady-state maximum temperature depends on the surrounding temperature. In this particular case, although lenses are far away from the breeder blanket, they are surrounded by a gas at low density $\left(6 \mu \mathrm{g} \mathrm{cm}^{-3}[7]\right)$ and high temperature. Such a scenario was simulated considering only radiative losses and assuming a surrounding temperature of $600 \mathrm{~K}$. The pulsed steady-state solution is reached after 18000 pulses, which results in a steady-state maximum temperature of $744 \mathrm{~K}$.

The 2D temperature profile and stresses under steady-state conditions for LIFE. 2 are represented in figure $5(b)$. Because of the homogeneous heat deposition along $z$ and the small lens thickness, the temperature profile along this direction varies only by $6 \mathrm{~K}$. Concerning the $r$-axis, the temperature reaches a maximum of $744 \mathrm{~K}$ at $r=0$ and decreases down to $600 \mathrm{~K}$ at $r=35 \mathrm{~cm}$. This temperature gradient along $r$ leads to the generation of compression radial and azimuthal stresses of $-1.4 \mathrm{MPa}$ within the irradiated volume and a maximum azimuthal traction stress of $3.25 \mathrm{MPa}$ at the lateral 


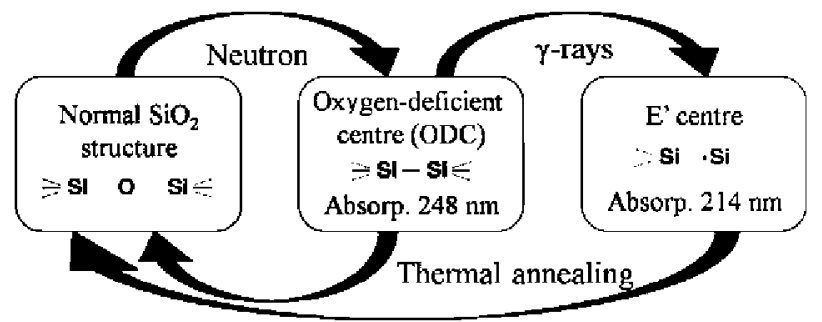

Figure 6. Schematic sketch of the colour centre formation and annihilation according to the model initially developed by Marshall et al [17].

surface $(r=35 \mathrm{~cm})$. In all cases, the calculated stresses are lower than those for HiPER prototype lenses and below the critical limit for silica (see table 3 ). In addition, the lenses of LIFE. 2 can withstand larger cracks $(32.12 \mathrm{~mm})$ than the lenses of HiPER facilities. Since, this value is higher than the thickness of lenses, the LIFE Fresnel lenses are not expected to suffer from brittle fractures. In conclusion, the LIFE Fresnel lenses (located far away from the explosions) can in principle withstand the radiation-induced thermo-mechanical loads. Nevertheless, it is important to remark that in these studies the effect of the surrounding gas on lenses has not been considered, which has to be carried out in order achieve a more precise picture.

\section{Colour centre formation}

As previously mentioned, irradiation induces point defect generation in silica. In this section the degradation of the lenses due to atomistic effects is studied using a model developed by Marshall et al [17] to account for the colour centre formation $[17,18,30]$. The model considers that neutron collisions with the silica network produce oxygen-deficient centres (ODCs) that can be radiolytically converted into $\mathrm{E}^{\prime}$ centres via gamma interaction. Moreover, both ODC and $\mathrm{E}^{\prime}$ centre can be annealed out if the temperature is high enough. A schematic view of the colour centre formation and annihilation is depicted in figure 6.

The colour centre evolution is estimated for the HiPER prototype facility by assuming that the lenses are simultaneously subjected to neutron and gamma irradiation (section 3) and their temperature is constant at $850 \mathrm{~K} . \mathrm{X}$ ray and ion fluxes are ignored. The calculated ODC and $\mathrm{E}^{\prime}$ concentrations accumulated at two different repetition rates are shown in figure 7 . It is observed that both the ODC and $\mathrm{E}^{\prime}$ centres are created in the first hundred nanoseconds after each explosion, see figure 7(a). Defect annealing takes place effectively at the mentioned temperature. In fact, defect saturation becomes evident beyond 1000 pulses at a repetition rate of $10 \mathrm{~Hz}$ and occurs after 150 pulses at $1 \mathrm{~Hz}$. The ODC concentration is always higher than that for $\mathbf{E}^{\prime}$ centres. This indicates that the $\gamma$-dose rate is too low to promote complete ODC conversion to $\mathrm{E}^{\prime}$ centres.

The absorption coefficient of the lenses $(\alpha)$ is related to the defect concentrations by the following equation

$$
\alpha(\lambda)=\sum_{i} \sigma_{i} N_{i} L_{i}(\lambda) \quad \text { with } L_{i}(\lambda)=\frac{1}{1+\frac{\left(\lambda_{i}-\lambda\right)^{2}}{\left(\Delta \lambda_{i}\right)^{2}}}
$$

where the subscript $i$ denotes a defect centre, $\sigma_{i}$ is the defect centre cross section, $N_{i}$ is the defect concentration, $\lambda$ is the wavelength, $\lambda_{i}$ is the peak wavelength for the defect centre $i$ and $\Delta \lambda_{i}$ is the half-width at half-maximum of the wavelength for the centre $i$. The absorption coefficients calculated at the fixed temperature $(850 \mathrm{~K})$ as a function of wavelengths for the HiPER prototype facility are shown in figure 8 . The parameters used for the calculations are listed in table 4 . Two peaks located at $248 \mathrm{~nm}$ and $214 \mathrm{~nm}$, corresponding to ODC and $\mathrm{E}^{\prime}$ centres, respectively, are clearly observed after the first 100 pulses. The intensity of both peaks notably grows with increasing pulse number until saturation (due to defect annealing) occurs for a pulse number higher than 1000 . This fact limits the lens absorption.

As previously mentioned, one of the main parameters of the lenses is the optical transparency in the $350 \mathrm{~nm}$ region. Because of this reason, the evolution of the lens absorption for different temperatures is studied. The optical absorption, $A$, is calculated by means of

$$
A=1-\exp (-\alpha(\lambda) d),
$$

where $d$ is the lens thickness. The results for HiPER experimental and prototype facilities are shown in figure 9. For the experimental facility, the optical absorption reaches $5 \%$ in about 2000 pulses for temperatures of 300 and $650 \mathrm{~K}$ and in 4000 pulses for a temperature of $700 \mathrm{~K}$. For temperatures higher than $700 \mathrm{~K}$, the optical absorption rapidly reaches an asymptotic value which is well below $1 \%$. For the prototype facility the optical absorption is higher than $5 \%$ after 850 pulses for $750 \mathrm{~K}$ and after 1300 pulses for $800 \mathrm{~K}$. The optical absorption saturates below $5 \%$ for $825 \mathrm{~K}$. And for temperatures higher than $850 \mathrm{~K}$, the absorption is below $1 \%$.

We can assume that $5 \%$ is the lens replacement limit. Lenses with such a reduced optical transmission will not fulfil the optical system requirements. Lens replacement or lens healing, e.g., by annealing [30] must be carried out. On the other hand, we can assume that $1 \%$ is the optimum operation limit, i.e. lens performance beyond this limit, may compromise the power plant operation. These results illustrate that (i) for the experimental facility the lens replacement limit is reached in 2000 pulses, i.e. the lifetime of silica final lenses operating at room temperature is comparable to the expected facility lifetime. In addition, increasing the lens temperature above $\sim 700 \mathrm{~K}$ would lead to a reduction of the optical absorption below the optimum operation limit. (ii) For the HiPER prototype facility, an optical absorption as low as $0.1 \%$ is estimated at steady-state operation temperature $(938 \mathrm{~K})$, i.e. much lower than the optimum operation limit. Moreover, under this scenario the optical absorption is observed to be above the optimum operation limit only if the temperature is lower than $\sim 850 \mathrm{~K}$. (iii) Only if the steady-state temperature in the HiPER demo facility could be controlled below the maximum service temperature, e.g., with an external cooler at $\sim 900 \mathrm{~K}$, the optical absorption would be lower than $0.5 \%$.

The absorption as a function of the pulse number calculated at different temperatures for the LIFE. 2 facility is shown in figure 10. Because of the small thickness of the lenses, the optical absorption for LIFE. 2 increases slower than in the case of HiPER facilities. In steady state the maximum temperature reaches $744 \mathrm{~K}$. Then, according to 

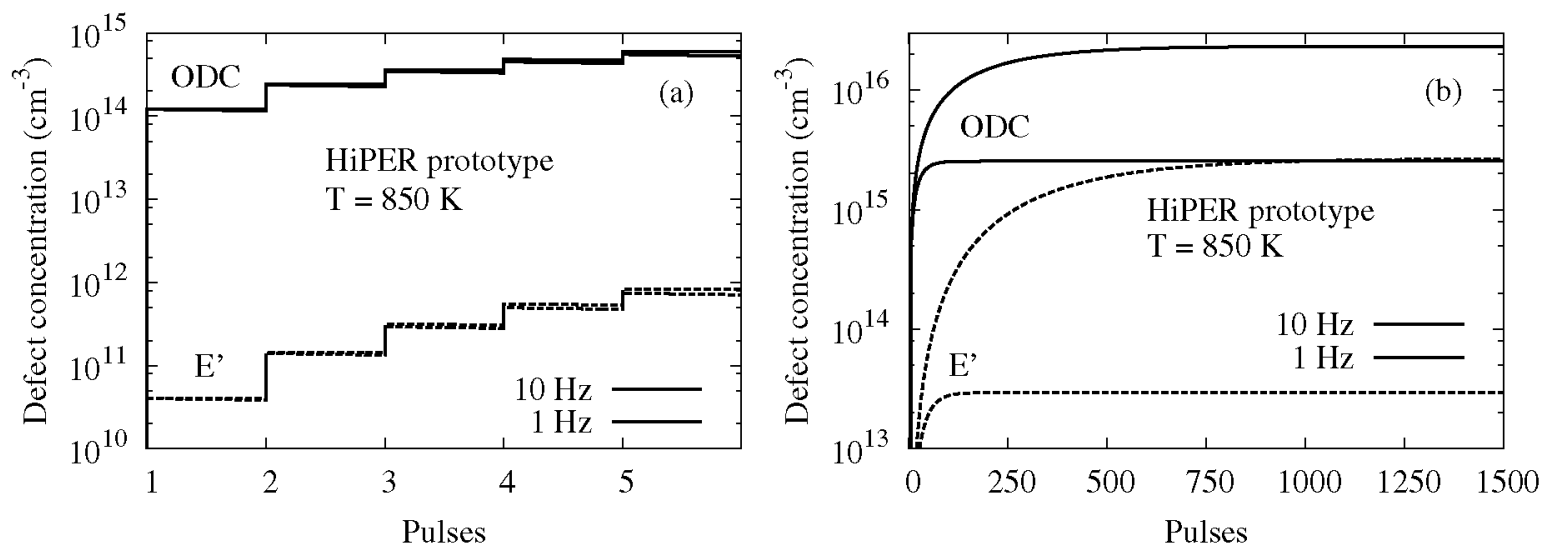

Figure 7. Concentration of oxygen-deficient centres (ODCs) and $\mathrm{E}^{\prime}$ centres accumulated in the final lens as a function of pulse number for a $50 \mathrm{MJ}$ yield target explosions, for two different repetition rates and for constant lens temperature (annealing temperature) of $850 \mathrm{~K}$.

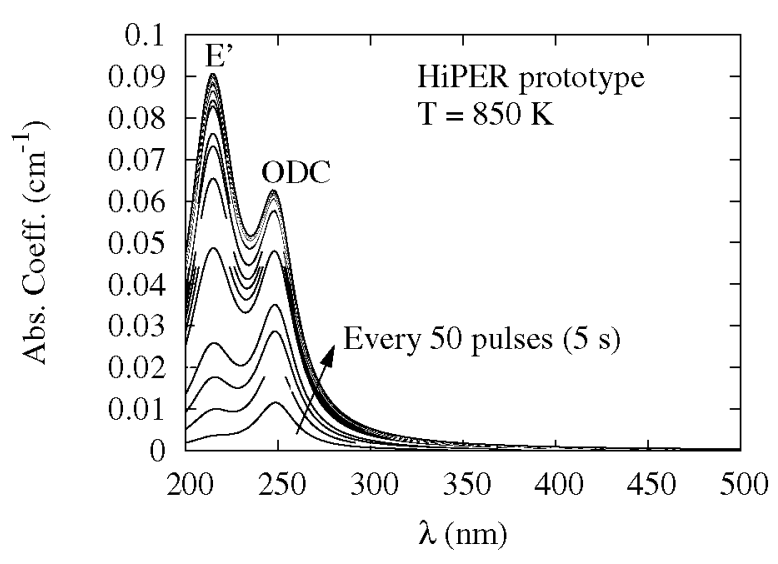

Figure 8. Absorption coefficient for a lens kept at $850 \mathrm{~K}$ during exposure to $50 \mathrm{MJ}$ target explosion at a rate of $10 \mathrm{~Hz}$ (prototype facility conditions). The lowest curve correspond to 50 pulses, and the highest to $1500(150 \mathrm{~s})$ (the curves are given every 50 pulses, $5 \mathrm{~s}$ ).

Table 4. Values used for the parameters of the model.

\begin{tabular}{lll}
\hline Parameter & Value & Ref. \\
\hline$\sigma_{\mathrm{ODC}}\left(\mathrm{cm}^{2}\right)$ & $1.7 \times 10^{-17}$ & {$[18]$} \\
$\lambda_{\mathrm{ODC}}(\mathrm{nm})$ & 248 & {$[39]$} \\
$\Delta \lambda_{\mathrm{ODC}}(\mathrm{nm})$ & 13 & {$[39]$} \\
$\sigma_{\mathrm{E}^{\prime}}\left(\mathrm{cm}^{2}\right)$ & $3.2 \times 10^{-17}$ & {$[40]$} \\
$\lambda_{\mathrm{E}^{\prime}}(\mathrm{nm})$ & 214 & {$[39]$} \\
$\Delta \lambda_{\mathrm{E}^{\prime}}(\mathrm{nm})$ & 15 & {$[39]$} \\
\hline
\end{tabular}

our calculations, the optical absorption is $3.9 \%$, close to the reported value of $3.5 \%$ [6]. At temperatures below $744 \mathrm{~K}$, the optical absorption is above the lens replacement limit (5\%) in about 20000 pulses at $650 \mathrm{~K}$ and in about 23000 pulses at $700 \mathrm{~K}$. The absorption remains below the optimum operation limit (1\%) for temperatures around $775 \mathrm{~K}$ and higher. Therefore, LIFE. 2 lenses will present an optical absorption below the lens replacement limit in steady-state operation. Moreover, the optical absorption can be reduced even further (below the optimum operation limit) if the lens temperature is somehow increased, e.g., by means of an external heater.

Finally, the design points for HiPER (prototype and demo) and LIFE. 2 facilities are depicted in figure 11. The colour map stands for the lens absorption. The design points for
HiPER prototype and demo facilities, when keeping somehow the operation temperature at $\sim 950 \mathrm{~K}$, are located in the lowabsorption region, being lower than the optimum operation limit $(0.1 \%$ and $0.5 \%$ for prototype and demo, respectively). Two operation points for LIFE. 2 are shown: (i) the so-called beam heating which corresponds to the case calculated in this section $(A=3.9 \%$ ) where the laser beam heating effect on the lenses is considered, (ii) external heater in which the lens temperature is assumed to be somehow increased above $850 \mathrm{~K}$ by an external heating source to reduce the optical absorption down to values of the order of $0.1 \%$ below the optimum operation limit.

\section{Reactor startup and optical restrictions}

In the previous section, the strong dependence of the radiationinduced changes in the optical properties of the lenses has been illustrated. This dependence turns out to be a critical point during the reactor startup process in which operation temperatures are low.

To study the lens behaviour during the reactor startup, the temperature (along $z$ ) and the colour centre concentration are calculated by means of a simplified 1D model. For these calculations the neutron and gamma dose rates, the neutron flux, as well as the silica properties (mean free path and the number of defects formed following a primary knock on the atom) are considered to be constant. The deposited laser energy is calculated every time step taking into account the absorption due to the concentration of colour centres.

The time evolution of the lens absorption during the startup process for the different facilities is shown in figure 12. For the prototype facility, an absorption as high as $17 \%$ is estimated during the first $400 \mathrm{~s}$. After this time the optical absorption rapidly decreases by $\sim 2 \%$ for times longer than $1200 \mathrm{~s}$. This behaviour can be explained by considering that during the first seconds a large number of colour centres are formed. In principle, one should expect the colour centre density to become larger when increasing time (increasing the number of shots), but this only holds if the lens temperature is low enough to prevent colour centre annealing. When the lens temperature is above a certain limit for colour centre annihilation to happen, the average colour centre concentration at any given moment 

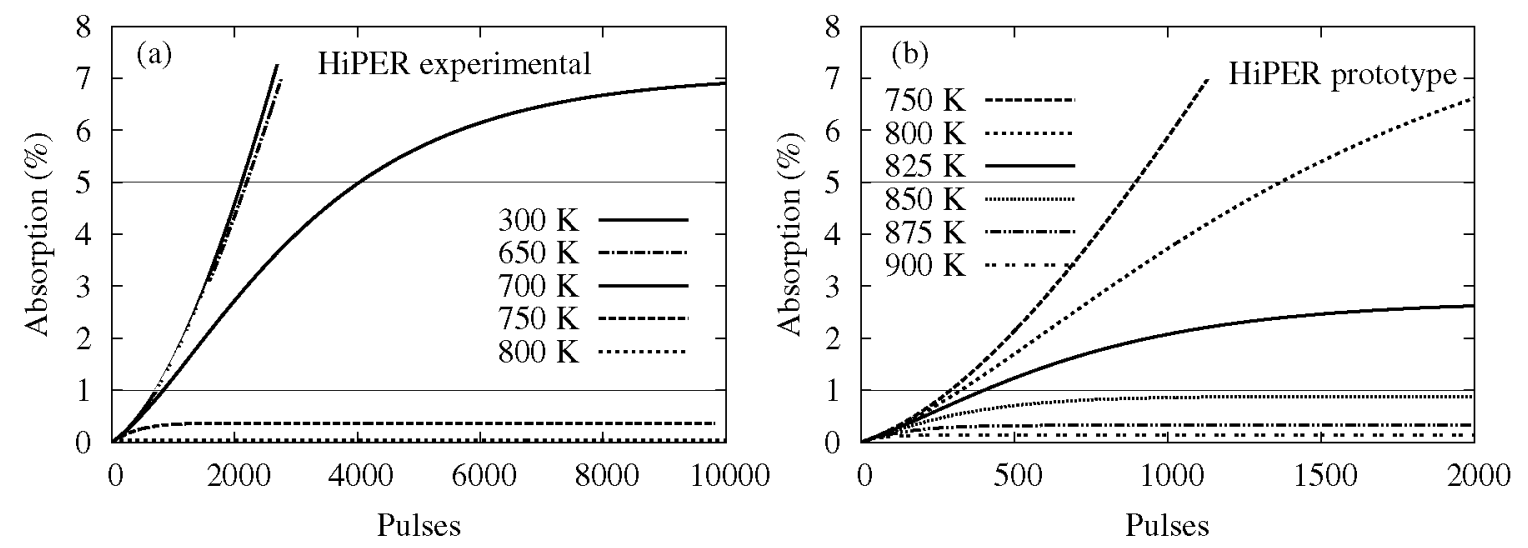

Figure 9. Optical absorption of a $5 \mathrm{~cm}$ thick silica lens at $\lambda=350 \mathrm{~nm}$ for different temperatures with a $20 \mathrm{MJ}$ yield target and a repetition rate of $0.5 \mathrm{~Hz}$ in the experimental facility $(a)$, and in the prototype facility with a $50 \mathrm{MJ}$ yield target and a repetition rate of $10 \mathrm{~Hz}(b)$.

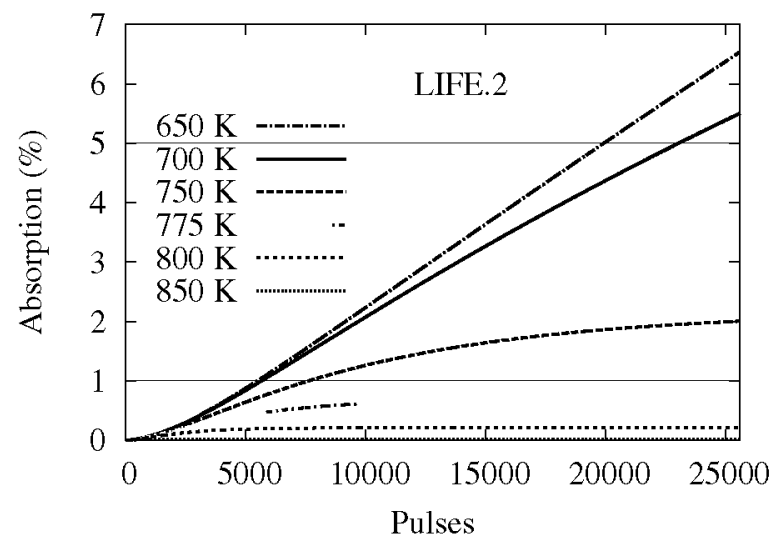

Figure 10. Optical absorption of a LIFE. 2 final lens at $\lambda=350 \mathrm{~nm}$ for different temperatures with a $132 \mathrm{MJ}$ yield target and a repetition rate of $16 \mathrm{~Hz}$

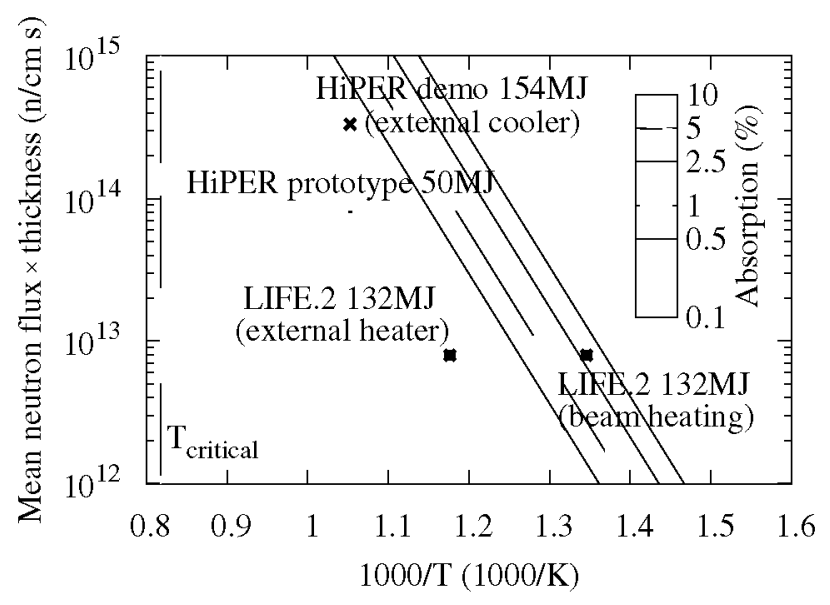

Figure 11. Parametric representation of the different HiPER and LIFE. 2 facilities. The colour map indicates the absorption, the $x$-axis is the inverse of lens temperature and the $y$-axis is the mean neutron flux (by primary neutrons) multiplied by the lens thickness.

depends on its formation and annihilation rate. Thus, the data shown in figure 12 illustrate that for times longer than $400 \mathrm{~s}$ the colour centre annihilation rate is higher than the formation one and therefore, the lens absorption decreases. The fact that the absorption coefficient during the first states of the startup process is significantly higher than the lens replacement limit (5\%) might impede the startup of the reactor. A possible solution to avoid such an absorption enhancement may be to use an external heater to increase somehow the lens temperature during the startup process. As shown in figure 12 , external heating of the lenses at a temperature of $850 \mathrm{~K}$ reduces the optical absorption to acceptable limits. After the initial moments (around 2000s) the absorption coefficient asymptotically decreases to reach the steady-state value below the optimum operational limit (1\%). Note that the absorption calculated during the startup does not saturate to the values previously calculated in continuous mode due to the assumptions of the simplified 1D model. However, this does not affect the main conclusion, i.e. unless we make use of an external heater the HiPER lens absorption will become unacceptably high during startup.

A very different time evolution of the optical absorption is observed for the Fresnel lenses of LIFE.2. In general, absorption increases smoothly, even during the initial stages, being below the lens replacement limit $5 \%$ at any given time, see figure 12. In view of these results, the Fresnel lenses would properly work in the HiPER demo facility. Figure 12 shows a simulation of the optical absorption evolution exchanging HiPER lens for a Fresnel lens in HiPER demo reactor with its operational mode. Calculations demonstrate that a reduction in the lens thickness from 5 to $0.5 \mathrm{~cm}$ would prevent the absorption enhancement during the startup process, keeping the optical absorption below $2 \%$ for all times.

\subsection{Focal length and aberrations in the HiPER lenses}

We need to address the dependence of the refractive index on temperature because a variation in the refractive index affects the focal length of the lens and therefore, the ignition process itself. The focal length is calculated by means of the thick lens equation in vacuum

$$
\frac{1}{f}=\left(n_{s}-1\right)\left(\frac{1}{r_{1}}-\frac{1}{r_{2}}\right)+\frac{d\left(n_{s}-1\right)^{2}}{n_{s} r_{1} r_{2}},
$$

where $n_{s}$ is the refractive index, $r_{1}$ is the radius of curvature of the lens surface closest to the light source and $r_{2}$ the radius of curvature of the lens surface farthest to the light source. The focal length is one half the distance between the lens and 


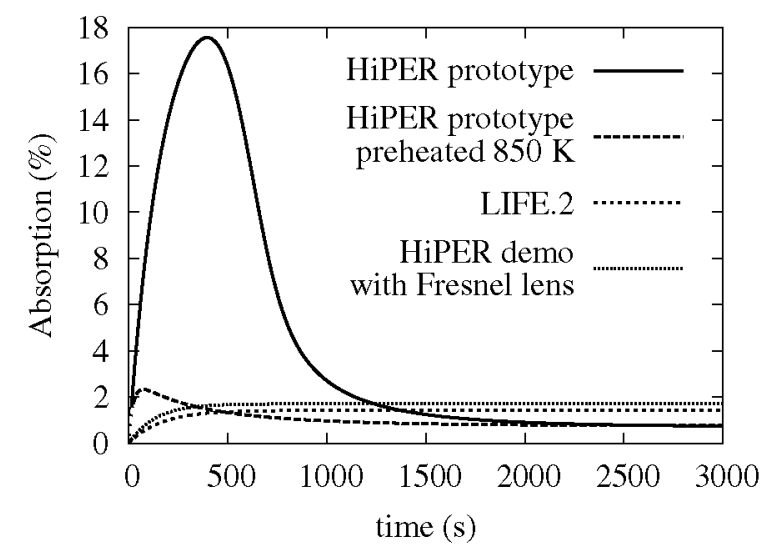

Figure 12. Calculated lens absorption evolution during the startup process for HiPER (prototype and demo) and LIFE. 2 facilities. For the calculations the surrounding temperature is assumed to be constant and equal to $600 \mathrm{~K}$.

Table 5. Refraction index for the indicated temperatures (from [41]) and the resulting focal length for biconvex HiPER lenses.

\begin{tabular}{lll}
\hline Temperature $(\mathrm{K})$ & $\begin{array}{l}\text { Refraction index } \\
\text { at } 350 \mathrm{~nm}\end{array}$ & Focal length $(\mathrm{cm})$ \\
\hline 600 & 1.47888 & 400 \\
760 & 1.48110 & 398.2 \\
938 & 1.48346 & 396.2 \\
\hline
\end{tabular}

the chamber centre, i.e. $f=4.0 \mathrm{~m}$ in HiPER facilities. In addition, we consider that HiPER lenses are biconvex with a focal length of $4 \mathrm{~m}$ at $600 \mathrm{~K}$ and $r_{1}=-r_{2}=382.3 \mathrm{~cm}$. In the worst case of the HiPER prototype facility, the lens temperature increases from $600 \mathrm{~K}$ (surrounding temperature) to $938 \mathrm{~K}$ (the steady-state operation temperature). As shown in table 5, such an enhancement leads to an increase in the refraction index of 0.00458 . From these data a variation in the focal length of $3.8 \mathrm{~cm}$ is estimated by assuming that the lens geometry is fixed ( $r_{1}$ and $r_{2}$ constants) and by interpolating the refraction index for the experimental data in [41]. This variation in the focal length drives a notable increase in the laser spot diameter at the target position. When the focal length varies by $3.8 \mathrm{~cm}$, the laser spot diameter becomes $5.75 \mathrm{~mm}$ due to the geometrical configuration of the laser beam. The resulting spot diameter exceeds by far the $200 \mu \mathrm{m}$ sized spot required for ignition. This requirement implies that the focal length must not vary more than $1.3 \mathrm{~mm}$. Therefore, the lens system must be designed to keep the focal length variation within this limit. The most appropriate solution is to use an external heater to keep constant the lens temperature during the startup.

In figure $5(a)$ one observes that the temperature varies along both the $z$-axis (axial direction) and $r$-axis (radial direction). The best way of determining the impact of the temperature profile on the optical properties of a light beam is to calculate the optical path difference across the optic, which leads to the appearance of different types of aberrations. The temperature profile along the $z$-axis presents a variation of about $100^{\circ}$ in steady-state operation, see figure $5(a)$. This leads to the appearance of a small aberration effect. Along the radial direction, the temperature varies from $938 \mathrm{~K}$ in the centre to $760 \mathrm{~K}$ at $r=30 \mathrm{~cm}$ (corresponding to the laser edge).
This temperature profile introduces a longitudinal aberration of $4 \mathrm{~cm}$ at $8 \mathrm{~m}=2 f$ (the chamber centre). This corresponds to a transversal aberration of $3 \mathrm{~mm}$. This aberration impedes reaching the required laser spot diameter of $200 \mu \mathrm{m}$. A way to mitigate this aberration is to allow neutrons to reach an area larger than the laser area to produce a smoother radial temperature profile.

Another important feature is that the temperature profile reached at steady-state solution into the lens of the HiPER prototype facility induces a surface deformation. Small deformations move the focal length beyond the target point. In the prototype facility, the lateral surface has an axial displacement of $30 \mu \mathrm{m}$. Assuming a spherical lens, the sagitta of the spherical surface can be obtained by $s=$ $r-\sqrt{r^{2}-(D / 2)^{2}}$, where $r$ is the radius of the spherical surface and $D=0.75 \mathrm{~m}$ is the diameter of the lens. After the surface deformation, the final radius of the spherical surface $r_{\mathrm{f}}$ can be calculated taking into account the sagitta variation $\wedge s=30 \mu \mathrm{m}$,

$$
r_{\mathrm{f}}=\frac{(D / 2)^{2}+(s \pm \Delta s)^{2}}{2 s} .
$$

We have calculated the focal length of the deformed lens with the thick lens equation in vacuum (5). This curvature variation is feasible for a biconvex thick lens $\left(r_{1}=-r_{2}\right)$ because a negligible focal length variation is induced $(<50 \mathrm{~nm})$. In the case of a converge meniscus thick lens, with $4 \mathrm{~m}$ focal length and $r_{2}=8 \mathrm{~m}$ its focal length varies up to $0.1 \mathrm{~mm}$. In both cases (biconvex and converge lenses) the focal length variation is within the acceptable limit $(1.3 \mathrm{~mm})$.

In conclusion, although most of the optical restrictions induced by the thermo-mechanical response in HiPER lenses can be corrected with external heating systems, a new scheme for the final optical components must be studied for a proper performance of a future power plant.

\section{Conclusions}

A systematic study on the response of HiPER and LIFE final lenses under realistic irradiation conditions is presented in this paper. HiPER experimental (20 MJ explosions in bunch mode), prototype (50 MJ explosions in continuous mode) and demo (154 MJ explosions in continuous mode) scenarios as well as the LIFE.2 (132 MJ explosions in continuous mode) scenario are considered to calculate the radiation fluxes. LIFE will employ indirect targets. Their explosion generates a prompt x-ray pulse so intense that no material can withstand it. As a radiation mitigation strategy LIFE has adopted the use of chambers filled with residual gas. Therefore, from the point of view of the final lenses the major irradiation threads are related to the arrival of neutron and gamma pulses. On the other hand, HiPER will employ direct targets, which generate an intense ion pulse that target-facing materials must withstand. In this case, residual gas mitigation strategies cannot be adopted due to incompatibilities with the target injection. However, thermo-mechanical calculations show that the ion pulses in every HiPER scenario lead to a final lens temperature above the silica melting temperature. Therefore, some sort of mitigation strategy, not described in this paper, will be necessary to get rid of the ion irradiation of the final lenses. 
Disregarding ions, the remaining $\mathrm{x}$-ray, neutron and gamma irradiation is observed to increase the HiPER lens temperature after every shot. The estimated temperatures in steady-state conditions are below the maximum silica service temperature for HiPER experimental and prototype facilities and above that temperature for the HiPER demo facility. This must be a major consideration for the design of the HiPER demo reactor optical system. In the case of LIFE.2 the position of the final lenses in addition to the residual gas makes it possible to maintain the lens temperature below the maximum silica service temperature.

The temperature profiles along the $z$ and $r$ directions lead to stress generation. In all cases the calculated stresses are observed to be lower than the silica tensile strength (48 MPa), which indicates that, silica lenses can withstand the radiationinduced mechanical stresses. The critical crack length for brittle fracture is calculated to be $6.6 \mathrm{~mm}, 2.04 \mathrm{~mm}$ for HiPER prototype and demo facilities, respectively. The lenses in HiPER experimental and LIFE. 2 facilities will not suffer from brittle fracture since the estimated critical crack length is larger than the dimensions of the maximum traction volume of the lens. The estimated stress intensity factor range is significantly smaller than the silica fatigue threshold, which indicates that negligible crack growth due to cyclic traction stress will take place in any facility.

Particle and purely ionizing radiation generate colour centres. The concentration of colour centres (oxygen-deficient centres (ODC) and $\mathrm{E}^{\prime}$ centres) at a given moment depends on their formation/annihilation ratio, which ultimately depends on temperature. The optical absorption at $350 \mathrm{~nm}$ (laser wavelength) depends on colour centre concentration. In steady-state operation, the optical absorption is calculated to be lower than the optimum operation limit $(1 \%)$ for the different HiPER reactors. In the case of LIFE.2, this also occurs provided that an external heater keeps the lenses at a temperature above $775 \mathrm{~K}$.

We also discuss the lens performance during HiPER reactor startup. We show that before reaching steady-state conditions the optical absorptions is unacceptably high, it exceeds the lens replacement limit $(5 \%)$ because the lenses are very cold. Some strategies must be used, for example, the use of external heating to pre-heat the lenses at temperatures of about at least $850 \mathrm{~K}$. Alternatively, Fresnel lenses (as in LIFE) appear to be less prone to excessive optical absorption during startup. The focal length variation during startup is another important issue. The temperature variation during startup leads to changes in the refractive index and therefore in the focal length that turn out to be unacceptable. Once again the proper use of an external heater could be used to keep the lens at a constant temperature during the startup procedure. Once steady state is reached, temperature profiles along both axes may produce aberrations. A way to make the temperature profiles as smooth as possible is to irradiate an area larger than the laser area or reduce the lens thickness (Fresnel lens option). In summary, we have addressed a number of fundamental and technological problems related to the performance of silicabased lenses in LIFE and HiPER laser fusion facilities. Some problems have been identified and some solutions have been proposed to overcome them. Nevertheless, further work is needed in order to find out optimum technological feasible solutions.

\section{Acknowledgments}

The authors thank the Spanish Ministry of Science and Innovation for economical support via ACI2009-1040 and AIC-A-2011-0718 projects.

\section{References}

[1] Le Garrec B. et al 2011 HiPER laser reference design Proc. SPIE $808080801 \mathrm{~V}$

[2] Perlado M. et al 2011 IFE plant technology overview and contribution to HiPER proposal Proc. SPIE $808080801 \mathrm{Z}$

[3] Rus B. et al 2011 Repetition rate target and fusion chamber systems for HiPER Proc. SPIE $\mathbf{8 0 8 0} 808020$

[4] Anklam T.M., Dunne M., Meier W.R., Powers S. and Simon S. 2011 LIFE: the case for early commercialization of fusion energy Fusion Sci. Technol. 60 66-71

[5] Dunne M. et al 2011 Timely delivery of Laser Inertial Fusion Energy (LIFE) Fusion Sci. Technol. 60 19-27

[6] Bayramian A. et al 2011 Compact, efficient laser systems required for Laser Inertial Fusion Energy Fusion Sci. Technol. $6028-48$

[7] Latkowsky J.F. et al 2011 Chamber design for the laser inertial Fusion Energy (LIFE) Engine Fusion Sci. Technol. 60 $54-60$

[8] Bourgade J.L. et al 2008 Diagnostic components in harsh radiation environments: possible overlap in $R \& D$ requirements of inertial confinement and magnetic fusion systems Rev. Sci. Instrum. 79 10F304

[9] Vukolov K.Y. 2009 Radiation effects in window materials for ITER diagnostics Fusion Eng. Des. 84 1961-3

[10] Primak W., Fuchs L.H. and Day P. 1953 Radiation damage in insulators Phys. Rev. 92 1064-5

[11] Friebele E.J., Griscom D.L., Stapelbroek M. and Weeks R.A. 1979 Fundamental defect centers in glass: the peroxy radical in irradiated, high-purity, fused silica Phys. Rev. Lett. 42 1346-9

[12] León M., Martin P., Bravo D., López F.J., Ibarra A., Rascón A. and Mota F. 2008 Thermal stability of neutron irradiation effects on KU1 fused silica J. Nucl. Mater. 374 386-9

[13] Griscom D.L., Gingerich M.E. and Friebele E.J. 1993 Radiation-induced defects in glasses: origin of power-law dependence of concentration on dose Phys. Rev. Lett. 71 1019-22

[14] Imai H., Arai K., Isoya J., Hosono H., Abe Y. and Imagawa H. 1993 Generation of E' centers and oxygen hole centers in synthetic silica glasses by $\gamma$ irradiation Phys. Rev. B 48 3116-23

[15] Hosono H., Mizuguchi M., Kawazoe H. and Ogawa T. 1999 Effects of fluorine dimer excimer laser radiation on the optical transmission and defect formation of various types of synthetic $\mathrm{SiO}_{2}$ glasses Appl. Phys. Lett. $742755-7$

[16] Skuja L., Hirano M., Hosono H. and Kajihara K. 2005 Defects in oxide glasses Phys. Status Solidi c 2 15-24

[17] Marshall C.D., Speth J.A. and Payne S.A. 1997 Induced optical absorption in gamma, neutron and ultraviolet irradiated fused quartz and silica $J$. Non-Cryst. Solids 212 59-73

[18] Latkowski F., Kubota A., Caturla M.J., Dixit S.N., Speth J.A. and Payne S.A. 2003 Fused silica final optics for inertial fusion energy: radiation studies and system-level analysis Fusion Sci. Technol. $\mathbf{4 3}$ 540-58

[19] Griscom D.L. 1991 Optical properties and structure of defects in silica glass J. Ceram. Soc. Japan 99 923-42

[20] Weeks R.A. 1994 The many varieties of E' centers: a review J. Non-Cryst. Solids 179 1-9

[21] Afanas'ev V.V. and Stesmans A. 2000 Charge state of paramagnetic E' centre in thermal $\mathrm{SiO}_{2}$ layers on silicon J. Phys.: Condens. Matter 12 2285-90

[22] Le Garrec B. et al 2011 HiPER laser: from capsule design to the laser reference design Proc. SPIE 7916 79160F 
[23] Juárez R., Sanz J., Sánchez C., Hernández J., Zanzi C. and Perlado J.M. 2011 Assessment of neutronics and heat parameters of a self cooled Lead Lithium blanket for HiPER reactor Proc. 7th Int. Conf. on Inertial Fusion Science and Applications (Bordeaux, France, 12-16 September 2011) at press, www.epj-conferences.org/

[24] Raffray A.R., Elguebaly L., Federici G., Haynes D., Najmabadi F., Petti F. and ARIES-IFE team 2004 Dry-wall survival under IFE conditions Fusion Sci. Technol. 46 417-37

[25] Álvarez J., Rivera A., González-Arrabal R., Garoz D., del Rio E. and Perlado J.M. 2011 Materials research for HiPER laser fusion facilities: chamber wall, structural material and final optics Fusion Sci. Technol. $60565-9$

[26] Najmabadi F., Raffray A.R. and ARIES-IFE team 2004 Operational windows for dry-wall and wetted-wall IFE chamber Fusion Sci. Technol. 46 401-16

[27] Pelowitz D.B. 2005 MCNPX User's Manual and Extension LA-CP-05-0369

[28] Wu Y. and FDS Team 2009 CAD-based interface programs for fusion neutron transport simulation Fusion Eng. Des. 84 1987-92

[29] Chadwick M.B. et al 2006 ENDF/B-VII.0: Next Generation Evaluated Nuclear Data Library for Nuclear Science and Technology Nucl. Data Sheets 107 2931-3060

[30] Rivera A., Garoz D., Juárez R., Álvarez J., González-Arrabal R. and Perlado J.M. 2011 Lifetime of silica final lenses subject to HiPER irradiation conditions Proc. SPIE $791679160 \mathrm{~S}$

[31] Álvarez J., González-Arrabal R., Rivera A., del Río E., Garoz D., Hodgson E.R., Tabares F., Vila R. and Perlado M.
2011 Potential common radiation problems for components and diagnostics in future magnetic and inertial confinement fusion devices Fusion Eng. Des. 86 1762-5

[32] Heltemes T.A., Prochaska A.E. and Moses G.A. 2010 Simulating thermo-mechanical interaction between a xenon gas-filled chamber and tungsten first-wall armor for the LIFE reactor design using the BUCKY 1-D radiation hydrodynamics code J. Phys. Conf. Ser. $\mathbf{2 4 4} 032032$

[33] Ziegler J.F., Biersack J.P. and Littmark U. 1985 The Stopping and Ranges of Ions in Solids (New York: Pergamon)

[34] Abbas M. and EDF R\&D 2008 Manuel d'utilisation: introduction au Code_Aster. Electricité de France www.code-aster.org/V2/doc/v9/fr/man_u/u1/u1.02.00.pdf

[35] Blanchard J.P. and Raffray R. 2007 Laser fusion chamber design Fusion Sci. Technol. 52 440-4

[36] Bower A.F. 2010 Applied Mechanics of Solids (Boca Raton, FL/London: CRC Press/Taylor and Francis)

[37] Wiederhorn S.M., Johnson H., Diness A.M. and Heuer A.H. 1974 Fracture of grass in vacuum J. Am. Ceram. Soc. $57336-41$

[38] Sglavo V.M. and Green D.J. 2001 Fatigue limit in fused silica J. Eur: Ceram. Soc. 21 561-7

[39] Kuzuu N 1994 X-ray induced absorption bands in synthetic fused silicas: $\mathrm{OH}$ content dependence of intensities of $\mathrm{x}$-ray-induced absorption bands in type-III fused silicas J. Non-Cryst. Solids 179 170-8

[40] Skuja L. 1998 Optically active oxygen-deficiency-related centers in amorphous silicon dioxide J. Non-Cryst. Solids 239 16-48

[41] Wray J.H. and Neu J.T. 1969 Refractive index of several glasses as a function of wavelength and temperature $J$. Opt. Soc. Am. 59 774-6 